\title{
SITE TRIALS OF RECYCLED AND SECONDARY AGGREGATES IN CONCRETE AND CONCRETE BLOCKS IN QATAR
}

\author{
Dr. K. E. Hassan, TRL, QSTP-B, Doha, Qatar. \\ Dr. M. S. Al-Kuwari, Qatar Standards, Ministry of Environment, Doha, Qatar.
}

Dr. J. M. Reid, Senior Technical Manager, Infrastructure, TRL, Crowthorne House, Nine Mile Ride, Wokingham, Berkshire RG40 3GA, United Kingdom.Email: jreid@trl.co.uk

doi: 10.2478/ijpeat-2013-0011

\begin{abstract}
A major construction programme is underway in Qatar. A shortage of local aggregate is focusing attention on the use of recycled and secondary aggregates. Site trials using locally available materials in structural concrete and concrete blocks were carried out in three small buildings. By far the largest source of recycled and secondary aggregates in Qatar is construction, demolition and excavation waste, which is generally crudely separated into excavation waste (EW) and construction/demolition waste (CDW). The other material investigated was incinerator bottom ash (IBA). The EW was used to replace $50 \%$ of the coarse aggregate in structural C40 concrete, with the CDW replacing $50 \%$ and IBA $20 \%$ of the coarse aggregate in non-load bearing concrete blocks. The control was $100 \%$ imported gabbro coarse aggregate. The trials also incorporated replacement of $60 \%$ of the local washed sand with imported crushed rock fines; this was investigated because the reserves of suitable concrete sand in Qatar are limited. Results after one year show the materials giving equivalent or better performance than the primary aggregate controls. The Qatar Construction Specification will be updated to permit greater use of recycled and secondary aggregates (RSA) and further trials are planned in a range of applications, including unbound subbase and pavement concrete. Wider use of these materials will reduce reliance on imported aggregates. The site trials won an award for the most innovative project from the Qatar Contractors Forum 2013.
\end{abstract}

\section{Introduction}

Qatar is a peninsula on the south shore of the Arabian Gulf, with a population of about 2 million. It has abundant reserves of natural gas and is experiencing a period of great economic growth, investing in major redevelopment of buildings and infrastructure, with major new rail and road projects and the stadia for the 2022 World Cup.

Construction in hot desert regions presents a number of challenges, one of which is ensuring a sustainable supply of suitable aggregates (Walker, 2012). In low-lying coastal regions such as Qatar, bedrock often consists of geologically recent sedimentary rocks. These are often highly variable in strength, mainly relatively weak limestone with some stronger bands (Fourniadis, 2010), and often with high concentrations of sulphates and chlorides. They are thus generally unsuitable as aggregates for high value applications such as concrete and asphalt. Bedrock is often overlain by sand deposits, but these also usually have high levels of sulphates and the 
grading may be unsuitable for fine aggregate in concrete. It may be possible to produce suitable sand for concrete from some deposits if they are washed to remove excess fines. However, coarse aggregates often have to be imported from the nearest available source, which may be some distance away.

Fine aggregate in Qatar is obtained from ancient river sand deposits, which are suitable for use in concrete if washed. Coarse aggregate, mainly gabbro, is imported for use in concrete and asphalt. This imposes major costs on construction, and the port capacity may be a constraint on the proposed rate of development.

One way to reduce dependence on imported aggregates is to make use of recycled and secondary aggregates. However, use of these materials in hot desert areas has been limited to date, especially for use in concrete (Abdelfatah and Tabsh, 2011; Walker, 2012). There has been some use of recycled aggregates in unbound applications in the Arabian Gulf; a recycled aggregate facility has been set up at Al Dhafra in Abu Dhabi and about 1.2 million tonnes of recycled aggregate has been used in the construction of the Etihad Railway Phase 1 (Construction Week Online, 2013).

The government of Qatar is aware of the potential tension between economic development and management of the environment, and the Qatar National Vision (2011) commits to ensuring that economic growth is balanced with protection of the environment. The Qatar National Development Strategy 2011 - 2016 (2012) affirms the importance of managing waste in line with the waste hierarchy and increasing the recycling of waste, and the Qatar National Research Strategy (2012) includes a specific objective to "develop improved approaches for solid waste management in Qatar, to include reducing waste generation, increasing waste recycling, and mitigating the adverse impacts of waste disposal". There is thus a strong policy basis supporting the use of recycled and secondary aggregates.

In response to this policy agenda, TRL QSTP-B, Qatar Standards and Qatar University are carrying out a research project for the Qatar National Research Fund (QNRF) at the Qatar Foundation to investigate the potential use of recycled and secondary aggregates. The results of a review of available materials and a programme of laboratory tests were presented by Hassan et al. (2013). This paper presents a brief update of this work and describes a site trial in the capital, Doha, demonstrating the use of various recycled and secondary aggregates in structural concrete and concrete blocks in three small buildings.

\section{Potential Recycled and Secondary Aggregates in Qatar}

\section{Materials}

Waste from the redevelopment of Doha is taken out into the desert to a site called Rawdat Rashid, where it is crudely separated into excavation waste (EW) and construction and demolition waste (CDW). The two materials are dumped in separate areas. The EW was reprocessed into aggregate for unbound applications on a small scale, but the operations stopped in 2012. In September 2013 a new contractor was appointed by the Ministry of Environment to produce recycled aggregates at the site. The EW is a relatively clean, white limestone with small but variable quantities of asphalt, wood, blocks and concrete. Most of the material contains a significant amount 
of fines, but also large particles of relatively strong limestone. The CDW is much more variable and is predominantly grey in colour. The main constituents are concrete and concrete blocks with some asphalt, steel, wood, glass, gypsum wallboard, ceramics and roofing.

The other materials potentially available for processing into recycled and secondary aggregates are incinerator bottom ash (IBA) and steel slag. IBA is produced at a modern Energy-from-Waste plant that processes municipal waste from Doha. The waste is burned at $850^{\circ} \mathrm{C}$ for 45 minutes and the ash is quenched in water then transported to an outdoor area where it is allowed to stand for about one month. It is then processed to remove metals and unburnt material and sent to a landfill on site. Samples of this material were obtained for laboratory testing. Samples of the steel slag were not available, so this material was not included in the testing programme.

A summary of the potential suitability of the various natural, recycled and secondary aggregates in Qatar is shown on Figure 1; this is based on an extensive programme of laboratory tests (Hassan et al., 2013). The tests showed that the EW could be suitable as coarse aggregates as a replacement for the primary aggregate in structural concrete and load bearing concrete blocks. The CDW is also potentially suitable for up to $50 \%$ replacement of primary aggregate but will require a higher degree of processing to remove lightweight contaminants like wood and plastic.

EW and CDW are not suitable for use as fine aggregate due to high content of fines, sulphate, chloride and lightweight pieces and high water absorption. They are suitable for use as unbound subbase if processed to remove contaminants.

The IBA was found to be suitable as unbound subbase and as coarse aggregate in concrete blocks up to a replacement level of $20 \%$ of the primary aggregate. It was not suitable as coarse or fine aggregate in concrete. The IBA would need processing to ensure it was properly weathered before use to prevent expansive reactions, and to remove lightweight contaminants.

\section{Quantities}

A review of the current and estimated future use of aggregates in Qatar and the potential availability of recycled and secondary aggregates was undertaken. The results were presented in Hassan et al. (2013). Updated versions of these figures are presented in Tables 1 and 2. The main change is that the estimate of the stockpile of construction, demolition and excavation waste has increased considerably; it was found that the site at Rawdat Rashid was formerly a limestone quarry and that this had been backfilled with construction, demolition and excavation waste. 


\begin{tabular}{|c|c|c|c|c|c|c|}
\hline Aggregate & 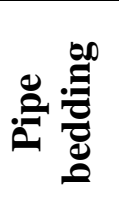 & 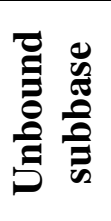 & 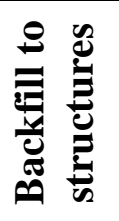 & 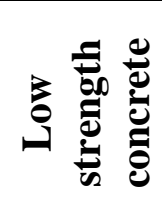 & 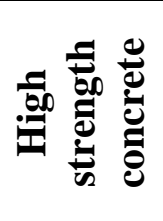 & 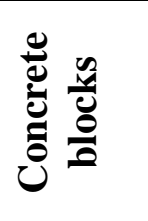 \\
\hline Imported gabbro & $\sqrt{ }$ & $\sqrt{ }$ & $\sqrt{ }$ & $\sqrt{ }$ & $\sqrt{ }$ & $\sqrt{ }$ \\
\hline Local limestone & $\sqrt{ }$ & $\sqrt{ }$ & $\mathrm{x}$ & $\sqrt{ }$ & $\mathrm{x}$ & $\sqrt{ }$ \\
\hline Local washed sand & $\sqrt{ }$ & $\mathrm{X}$ & $\mathrm{x}$ & $\sqrt{ }$ & $\sqrt{ }$ & $\sqrt{ }$ \\
\hline $\begin{array}{l}\text { Excavation waste } \\
\text { (coarse \& all-in) }\end{array}$ & $\sqrt{ }$ & $\sqrt{ }$ & $\mathrm{X}$ & $\sqrt{(50 \%)}$ & $\sqrt{(50 \%)}$ & $\sqrt{(50 \%)}$ \\
\hline $\begin{array}{l}\text { Construction and } \\
\text { demolition waste } \\
\text { (coarse } \& \text { all-in) }\end{array}$ & $\sqrt{ }$ & $\sqrt{ }$ & $\mathrm{x}$ & $\sqrt{(50 \%)}$ & $\sqrt{(50 \%)}$ & $\sqrt{(50 \%)}$ \\
\hline $\begin{array}{c}\text { Incinerator Bottom } \\
\text { Ash (coarse \& all-in) }\end{array}$ & $\mathrm{X}$ & $\sqrt{ }$ & $\mathrm{X}$ & $\mathrm{X}$ & $\mathrm{X}$ & $\sqrt{(20 \%)}$ \\
\hline $\begin{array}{c}\text { EW, CDW \& IBA } \\
\text { (fine) }\end{array}$ & $\mathrm{X}$ & $\mathrm{x}$ & $\mathrm{x}$ & $\mathrm{x}$ & $\mathrm{X}$ & $\mathrm{x}$ \\
\hline
\end{tabular}

Note: where the level of use is less than 100\%, the proposed maximum level of replacement of imported gabbro is shown in brackets, e.g. (50\%)

Figure 1. Potential suitability of aggregates in Qatar for different applications

The CDW and EW represent by far the largest potential source of recycled and secondary aggregates and could meet part of the demand for aggregates in unbound applications (principally subbase) and concrete. The IBA may best be used in concrete blocks as a partial replacement for primary aggregate. These measures would help to reduce the demand for imported coarse aggregate, but production would have to be on a very large scale to make a significant impact. Current figures indicate that about 20 million tonnes of aggregates were imported into Qatar in 2012 (QPMC, 2013).

Before production on anything like that scale could be considered, the viability of the recycled and secondary aggregates has to be established through site trials, particularly for use in high value applications such as concrete.

Table 1. Estimated current and future uses of construction materials in Qatar

\begin{tabular}{|c|c|c|}
\hline Construction uses & Usage in 2011 (Mt/y) & Future demand (Mt/y) \\
\hline Concrete & 25 & $40-50$ \\
\hline Asphalt & 3 & $10-15$ \\
\hline Unbound aggregate & 30 & $50-70$ \\
\hline Total & $\mathbf{5 8}$ & $\mathbf{1 0 0}-\mathbf{1 3 5}$ \\
\hline
\end{tabular}

Table 2. Availability of recycled and secondary materials in Qatar

\begin{tabular}{|c|c|c|}
\hline Material & Arising $(\mathbf{M t} / \mathbf{y})$ & Stockpile \\
\hline CDW \& EW & 12.5 & $80-100$ \\
\hline Steel slag & 0.2 & 2 \\
\hline IBA & 0.05 & 1 \\
\hline Total & $\mathbf{1 2 . 7 5}$ & $\mathbf{8 3 - 1 0 3}$ \\
\hline
\end{tabular}




\section{Crushed Rock Fines}

Fine aggregate for use in concrete is predominantly local river sand, which is washed before use to remove clay and other impurities. Reserves are estimated to be about 90 million tonnes (QPMC, 2011), and consumption is about 15 million tonnes per year, so there is a need to find alternative materials for this application. The EW, CDW and IBA are not suitable for use as fine aggregate, as indicated above. An alternative is the use of crushed rock fines (CRF) as a partial replacement for washed sand. A project to investigate this option was carried out by TRL QSTP-B, Qatar Standards and the Qatar Primary Materials Company (QPMC).

The properties of CRFs are different to those of natural sand, with higher fines content (passing $75 \mu \mathrm{m}$ ), more angular particle shape and rougher surface texture. These properties make the concrete mix less workable, and the higher fines content requires higher water content in the mix to maintain workability, potentially leading to lower strength. Natural river sand generally contains clay $(<2 \mu \mathrm{m})$ and silt $(2$ to $60 \mu \mathrm{m})$ particles. Crushed clean rock consists of silt particles with very little clay. Higher fines content can thus be tolerated in crushed rock fines and this is reflected by higher limits for fines for crushed rock in most specifications, including the Qatar Construction Specification (QCS, 2010). However, the QCS specifies more stringent requirements for fines than other Gulf Coast Council (GCC) and international specifications.

The quality of fines is generally assessed using the sand equivalent test, which could misjudge the suitability of CRF because of its high fines content. Additional testing with the methylene blue test may be more useful in assessing whether harmful clayey particles are present in the aggregate.

A laboratory testing programme was carried out on three types of fine aggregates: local washed sand; imported gabbro sand; and imported limestone sand. The results show that limestone and gabbro sands satisfy the QCS criteria with the exception of fines content (passing $75 \mu \mathrm{m}$ ). However, the fines are not likely to be harmful, as they do not contain any clay particles.

The results show that washed sand has a high content of acid soluble sulphate, higher than the limit in the QCS. The limestone and gabbro sands have much lower sulphate content, within the QCS limits. The low sulphate content of CRFs indicate the potential for reducing the overall sulphate content to acceptable levels by maximising the CRF content in the fine aggregate.

Laboratory trials of a C40 concrete mix were carried out with samples of limestone sand and gabbro sand replacing 50\%, 60\% and $75 \%$ of the washed sand and a control of $100 \%$ washed sand as fine aggregate. The coarse aggregate was imported gabbro. The compressive strength of the hardened concrete, determined in accordance with BS EN 12390-3 (2009) at 3, 7 and 28 days is shown in Figure 2. The results show that it is possible to replace the local washed river sand as fine aggregate by up to $60 \%$ with limestone or gabbro CRF with no detriment in performance; in fact, with $60 \%$ limestone CRF replacement, the cement content can be reduced by $10 \%$ with improved properties of compressive strength and water absorption. The amount of super plasticiser required to maintain adequate workability has to be adjusted, 
however and there were concerns that the mix with gabbro CRF may be too harsh, potentially being hard to work and leading to decreased durability. Limestone sand was therefore used for the site trial.



Figure 2. Effect of replacing washed sand with crushed limestone and gabbro sand on compressive strength of concrete

\section{Site Trial}

\section{Design}

Laboratory testing generally involves assessing numerous materials over a short time span. Laboratory results rank the materials tested against each other and allow decisions to be made about which materials merit further investigation in field trials. However, laboratory testing only gives an indication of how the comparative materials will perform and is no guarantee for in service performance. This is mainly due to the difference between the controlled laboratory conditions and small size of laboratory specimens and conditions on the construction site. It is also necessary to ensure that the material designed in the laboratory can be produced in the concrete plant, transported to site with acceptable workability, poured and compacted to the required criteria specified. The only way to assess this is to select a number of options from the laboratory investigation and to proceed to full site trials. The first site trial covered the use of recycled and secondary aggregates in concrete and concrete blocks.

The trial consisted of three small single storey buildings. The site is located in Doha at the intersection of B-Ring Road with Najma Street, Zone 25 and Street number 320. The site is within the premises of the Public Works Authority (Ashghal) compound. The structural design of the trials was carried out by local consultant Khatib and Alami. The three buildings are $2.5 \mathrm{~m} \times 2.5 \mathrm{~m}$ in plan. All rooms consist of a roof, roof beam, column and strip footing beam. The internal finishing slab is made up of a 150 $\mathrm{mm}$ slab on grade. The alternative aggregates were used to replace different proportions of natural aggregate in structural (C40) concrete and non load-bearing concrete blocks (average compressive strength 7.0 MPa). Details are given in Table 3. 
Table 3. Composition of concrete and blocks in site trials

\begin{tabular}{|c|c|c|c|}
\hline C40 concrete & Building 1 & Building 2 & Building 3 \\
\hline Ga\% (replacing & $\begin{array}{c}\text { Control (100\% } \\
\text { Gabbro and 100\% } \\
\text { washed sand) }\end{array}$ & $\begin{array}{c}60 \% \text { CRF } \\
\text { (replacing washed } \\
\text { sand) }\end{array}$ \\
\hline Concrete blocks & $\begin{array}{c}50 \% \text { CDW } \\
\text { (replacing Gabbro) }\end{array}$ & $\begin{array}{c}\text { Control (100\% } \\
\text { Gabbro and 100\% } \\
\text { washed sand) }\end{array}$ & $\begin{array}{c}20 \% \text { IBA } \\
\text { (replacing Gabbro) }\end{array}$ \\
\hline
\end{tabular}

\section{Materials}

Recycled aggregate materials were obtained from Rawdat Rashid landfill in spring 2013. The site holds a large amount of unprocessed excavation waste (EW) and construction \& demolition waste (CDW) (Table 2).

The site is owned by the Ministry of Environment and was managed by a local contractor who processed the waste by crushing and screening the materials into different sizes. Limited amounts of the recycled aggregate were reused by the construction industry, mainly as fill materials. The contractor stopped working on site when his contract expired in August 2012.

Due to the stoppage of operations on site, the existing stockpiles of EW and CDW were contaminated with wind-blown dust. Visual inspection of the stockpiles indicated the presence of large quantities of fines which were not observed with the freshly made stockpiles used for the laboratory investigation in 2012. Therefore, it was decided to screen the materials to remove excess fines.

The EW and CDW recycled aggregate were transported from Rawdat Rashid to a quarry at Al-Karaana, near the Saudi border. Care was taken to avoid mixing the recycled aggregate with the primary aggregate used in the quarry. The recycled aggregate went through a crusher, and the resulting material was then passed through a series of screens to obtain aggregates of the desired grade. The larger pieces that were rejected were returned to the crusher and subsequently re-screened, with the process continuing until the desired size was obtained. The EW and CDW were obtained in two different sizes of 5-10 and 10-20 mm.

Incinerator bottom ash (IBA) was obtained from the Domestic Solid Waste Management Centre (DSWMC) near Masaieed in a single size of 5-10 mm. The DSWMC site is also owned by the Ministry of Environment and managed by Keppel Seghers.

After processing, the EW aggregate was transported to the ReadyMix Qatar concrete plant in Mesaaied to be used in concrete production. The CDW and IBA aggregate were transported to Khalid Cement Industries Complex in the Industrial area of Doha for the production of concrete blocks. 


\section{Concrete Block Production}

CDW and IBA were used to partially replace gabbro as coarse aggregate for the production of concrete blocks. The Qatar Construction Specification - Section 13 Part 4 (QCS, 2010) allows the use of recycled aggregate to replace a maximum of $20 \%$ of the coarse aggregate in concrete blocks. In this investigation IBA was used to replace $20 \%$ of the gabbro coarse aggregate $(5-15 \mathrm{~mm})$, whereas CDW replaced $50 \%$. Hollow concrete blocks $(400 \times 200 \times 200 \mathrm{~mm})$ were manufactured for use as external non-load bearing walls with a minimum average compressive strength of $7.0 \mathrm{MPa}$, as per the requirement of QCS 2010.

The blocks were tested for compressive strength at 28 days. Four concrete blocks from each mixture of Control, CDW and IBA were tested in accordance to BS EN 771-3 (2011). The test results are shown in Table 4.

Table 4. 28 day compressive strength tests on non load-bearing concrete blocks

\begin{tabular}{|c|c|c|c|}
\hline Material & $\begin{array}{c}\text { Average strength } \\
(\mathrm{MPa})\end{array}$ & $\begin{array}{c}\text { Minimum strength } \\
(\mathrm{MPa})\end{array}$ & $\begin{array}{c}\text { Maximum strength } \\
(\mathrm{MPa})\end{array}$ \\
\hline CDW (50\%) & 9.9 & 9.19 & 10.4 \\
\hline IBA (20\%) & 9.0 & 8.4 & 9.71 \\
\hline Control (gabbro) & 11.0 & 9.34 & 13.97 \\
\hline QCS 2010 & 7.0 & 5.6 & N/A \\
\hline
\end{tabular}

The results comfortably met the specification requirements, although the CDW and IBA gave lower values than the gabbro control.

\section{Structural Concrete Production}

The performance of concrete is dependent on its composition, production, compaction and curing. Successful production gives careful consideration to mixing, adequate workability, and transportation to site. As the trials involved producing blends of primary and recycled aggregates, particular attention was given to the process to ensure that the concrete was properly produced.

The mix design was checked to make sure that the correct ingredients were used by the automated system located in the batching cabin system. The central mixer (Figure 3.2) was cleaned with water to remove any plastic concrete from the previous loading.

Because of the large difference between the $9 \mathrm{~m}^{3}$ drum capacity of the transit mixer and the normal volume of concrete dispatched to site, which was $2 \mathrm{~m}^{3}$, it was necessary to fill the drum with $200-500$ litres of chilled water $\left(4^{\circ} \mathrm{C}-10^{\circ} \mathrm{C}\right)$ before loading concrete to reduce the temperature inside the drum and prevent rapid moisture loss from the mix during transit. The cooling of the drum was required due to the small volume used in the trials, but will not be needed when full production of $9 \mathrm{~m}^{3}$ drum capacity is used.

The aggregates were then loaded to the allocated bins. In normal production only three materials are used (10mm gabbro, $20 \mathrm{~mm}$ gabbro and washed sand). Consequently only three of the bins shown in Figure 3.1 are used while the fourth is 
kept empty and only used when special mix designs that incorporate different size aggregates, such as $40 \mathrm{~mm}$ gabbro, are required.

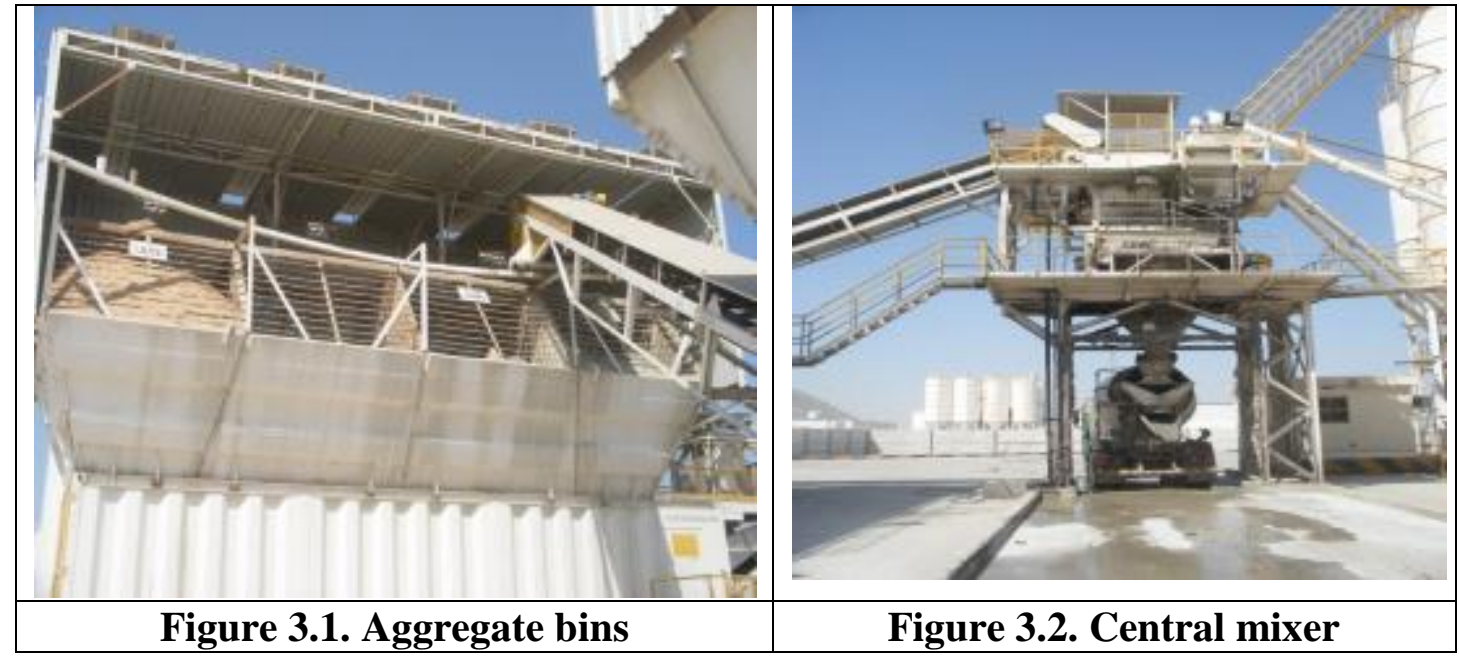

For the CRF concrete, the fourth bin was used for the CRF sand and weighed automatically, similar to the control concrete. For the EW concrete the number of bins was an issue, as the aggregate had to be pre blended in the required proportions before batching the concrete. A complex procedure was followed to pre blend the two different EW sizes in the required proportions before batching concrete with the blended aggregate. Due to the limited number of bins in the plant, the main challenge in this production process was mixing the two different sizes of EW aggregates. It was also noticed that some EW aggregate was getting crushed inside the mixer.

All aggregates and ice, to control mixture temperature, were added into the central mixer and mixed for 2-5 seconds. Cement, admixture and water were then added to the mix and mixed for 20-30 seconds until the concrete was ready. Aggregate water content was taken into consideration when determining the volume of water to use during mixing.

The required volume of concrete was batched and loaded to the transit mixer. The concrete was batched with the required quantity of ice to replace water to maintain the temperature at less than $32^{\circ} \mathrm{C}$ considering the transit time and day time temperature.

Finally before the concrete was dispatched to site, workability, plastic density, air content and temperature were tested in the lab.

\section{Concrete Mixtures}

Three different structural concrete mixtures were used with the compositions given in Table 5. The manufacture of the ready mix concrete and quality control testing were carried out by ReadyMix Qatar. The blinding concrete of C20 was made with $100 \%$ recycled materials $(80 \% \mathrm{EW}$ and $20 \% \mathrm{CDW})$. Crushed rock fines (CRF) of limestone sand were used to replace washed sand. 
Table 5. Structural concrete mixture design

\begin{tabular}{|c|c|c|c|}
\hline & $\begin{array}{c}\text { C40 } \\
\text { Control }\end{array}$ & $\begin{array}{c}\text { C40 } \\
\mathbf{5 0 \%} \text { EW }\end{array}$ & $\begin{array}{c}\text { C40 } \\
\text { 60\% CRF }\end{array}$ \\
\hline Cement (kg) & 370 & 370 & 335 \\
\hline Gabbro 20mm Aggregates (kg) & 719 & 360 & 735 \\
\hline Gabbro 10mm Aggregates (kg) & 480 & 240 & 489 \\
\hline Excavation waste (15-20mm) (kg) & 0 & 64 & 0 \\
\hline Excavation waste (5-15mm) (kg) & 0 & 458 & 0 \\
\hline CRF Limestone sand (kg) & 0 & 0 & 475 \\
\hline Washed sand (kg) & 750 & 750 & 325 \\
\hline Chemical admixture (1) & 3.53 & 4.4 & 4.6 \\
\hline Total water (1) & 181 & 191 & 177 \\
\hline Water to cement (w/c) & 0.446 & 0.446 & 0.446 \\
\hline
\end{tabular}

\section{Construction of Site Trial}

The site construction was carried out by a local contractor Qatari Arabian Construction Co. Construction commenced in early May 2013, where average daytime temperatures generally reached around $39^{\circ} \mathrm{C}$ and the average minimum temperature dropped at night to around $27^{\circ} \mathrm{C}$. The construction was completed by the middle of June 2013.

The delivery time from the plant to site ranged from 64 to 89 minutes, with an average time of 74 minutes. Slump values ranging from 210 to $230 \mathrm{~mm}$ were obtained at the ReadyMix plant with an average value of $220 \mathrm{~mm}$ and a range of 140 to $200 \mathrm{~mm}$ at site with an average of $170 \mathrm{~mm}$. The average slump reduction between tests carried at plant and site is $23 \%$. Despite the average 74 minutes delivery time, the concrete maintained adequate workability to be poured and compacted to the required standards.

The construction of the site trial is illustrated in Figures 4 to 6.

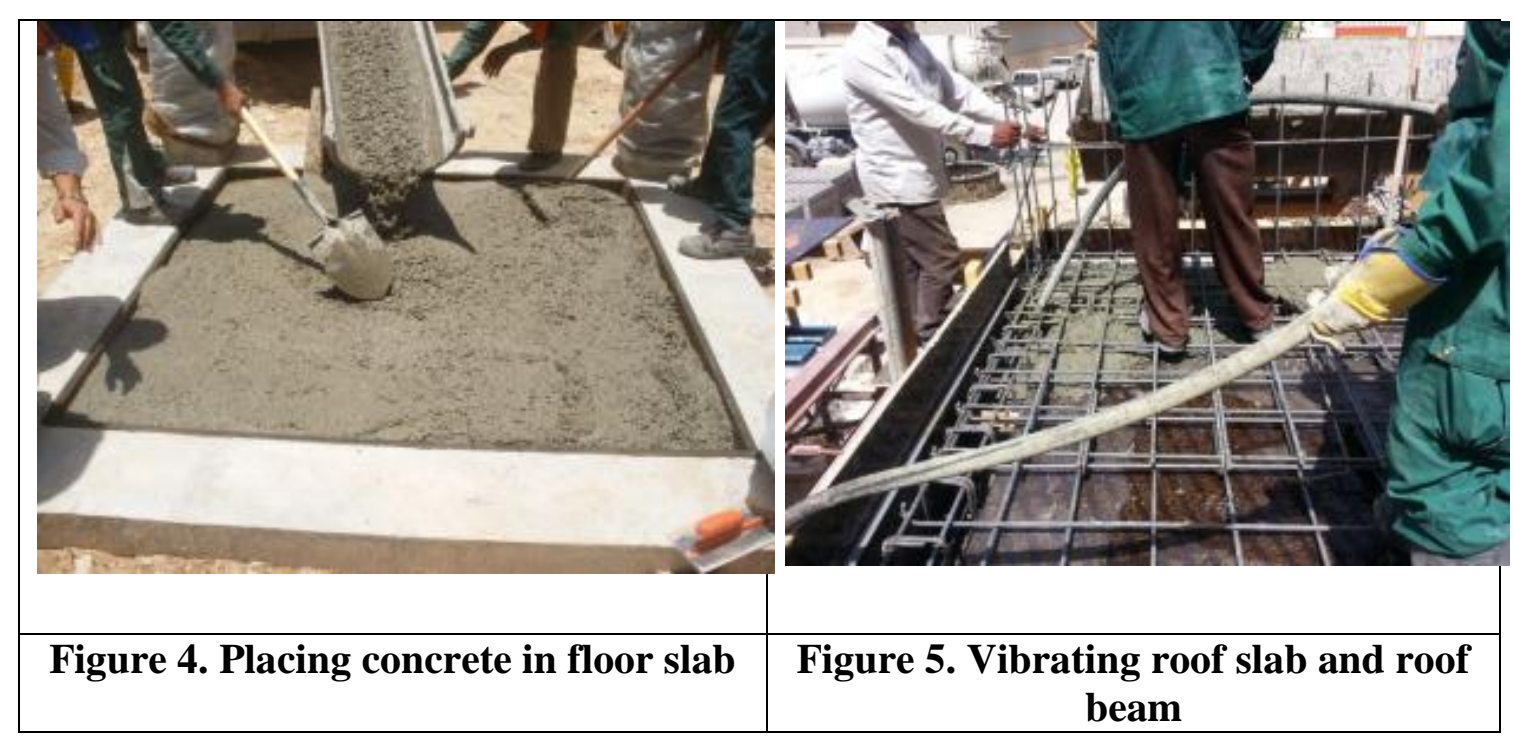




\section{Figure 6. Completed trial buildings and soakaway elements}

Curing is one of the main parameters influencing the properties and performance of concrete, especially in a hot environment such as Qatar. Fresh concrete exposed to a hot environment is liable to lose its mixing water due to evaporation. The loss of surface water by evaporation reduces the hydration of cement and results in a porous concrete surface cover. The concrete cover provides protection to the steel reinforcement from the penetration of harmful substances such as chloride ions. Therefore proper curing is essential for concrete durability in an aggressive environment.

Moist curing ensures the concrete surface is kept wet for continuous hydration. In this project, all concrete elements were wet cured for 7 days using wet hessian and polyethylene sheets. The hessian was sprayed 4 times every day to ensure a continuous moist concrete surface. The hessian was placed as soon as the concrete surface had hardened sufficiently to prevent surface damage. The polyethylene sheet was used to cover the wet hessian to form an effective barrier against water loss and evaporation.

General water curing was carried out by spraying water on the surface of concrete in a way that ensured it was kept continuously moist. Once sprayed, hessian clothing was used to cover the whole area of the structure to maintain water on the surface of the concrete. The use of hessian clothing was particularly useful since they reduce the rate of surface evaporation.

In addition to the concrete buildings, concrete elements were prepared to demonstrate the potential use of concrete made with alternative aggregate in various applications that are commonly used in the construction industry in Qatar. Soakaways, crash barriers, and concrete beams were constructed; some of the soakaway elements can be seen in Figure 6.

\section{Monitoring}

The next stage was to monitor the performance of the building trial and compare the performance of structural concrete and concrete blocks made with alternative and primary aggregates. The trial results were also used to validate the laboratory results carried out earlier in the project (Hassan et al., 2013). 
Concrete beams were prepared from the various concrete mixtures on site and cured with wet hessian and polyethylene sheets for 7 days. Cores were taken at 28 and 365 days to assess the performance of field concrete. Similarly, concrete cubes $(150 \mathrm{~mm})$ were prepared from the same concrete mixtures and tested at 3, 7, 28, 90 and 365 days.

Results from cubes for compressive strength properties and water absorption up to 365 days are given in Figures 7 and 8. The compressive strength tests were carried out in accordance with BS EN 12390-3 and the water absorption tests in accordance with BS 1881-122. The results indicate improved strength for the structural concrete and concrete blocks constructed with recycled and secondary aggregates, compared to the control constructed with primary gabbro aggregate. Figure 7 shows almost similar strength development for the EW concrete and the gabbro concrete and substantial improvement for the CRF concrete. Water absorption for the EW mix is slightly higher than for the control, and the CRF mix is slightly lower, but all three mixes on Figure 8 show a trend of decreasing water absorption with time.



Figure 7. Cube compressive strength of $\mathrm{C40}$ concrete from site trial

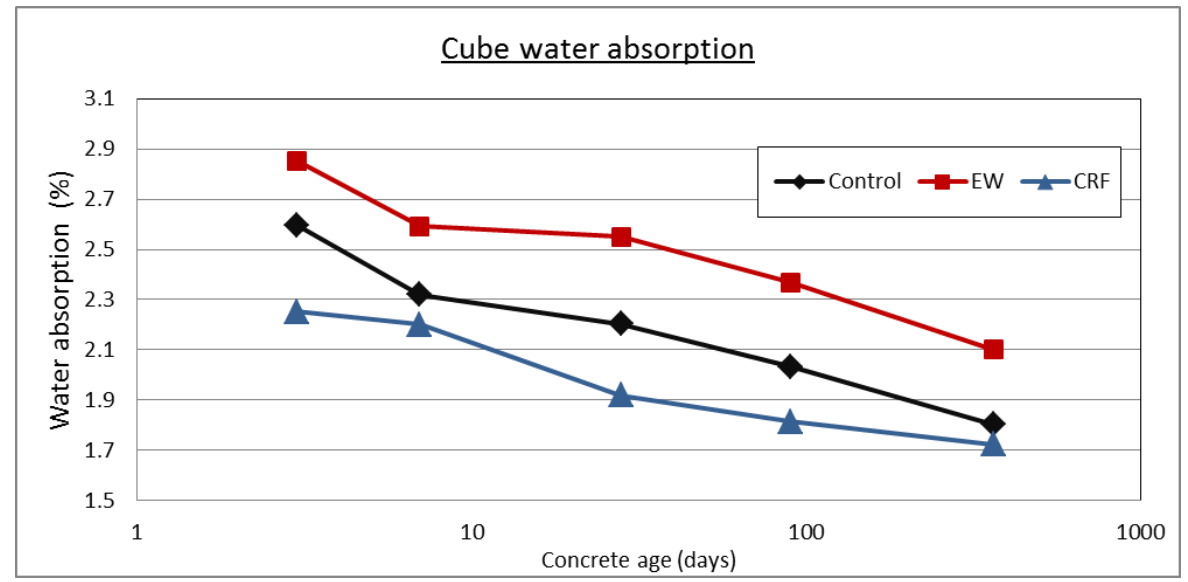

Figure 8. Water absorption results from site trial

Visual inspection of the trial buildings showed no signs of deterioration of the concrete or concrete blocks. Monitoring of the buildings will be continued to assess their long term durability. 


\section{Concrete Pavements}

The heavy traffic loading in Qatar and very high temperatures for much of the year necessitate the use of stiff pavement materials to minimise deformation of the pavement layers. Asphalt is commonly used in Qatar for surface and structural pavement layers, and is prone to deformation because the bitumen becomes very soft at high temperatures. Improved deformation resistance could be achieved by the use of concrete or hydraulically bound materials as the structural layers in the pavement.

The use of locally available recycled aggregate and cement in concrete pavements provides an attractive option compared to the import of bitumen and gabbro aggregate. The results obtained in this investigation demonstrate the successful use of recycled aggregate in the production of $\mathrm{C} 40$ concrete with at least similar performance to the control concrete made with imported gabbro. This supports potential use in concrete pavements.

Recycled aggregates could also be used as cement bound materials (CBM), provided that shrinkage and thermal cracks are controlled and not reflected through the asphalt surface course. There are also concerns about high sulphate content, particularly of the fine aggregate fraction of recycled aggregates (Hassan et al, 2013), which could potentially cause expansive reactions if used in CBM or other hydraulically bound materials. However, CBM has been used recently in major projects in Qatar, such as New Doha Port, Mesaimeer Road and Corniche Road, and its use is expected to increase with the use of recycled aggregate. The use of recycled aggregate in CBM requires further investigation.

\section{Unbound Subbase}

The major programme of infrastructure to 2022 will require very large quantities of unbound subbase. Local limestone has traditionally been used for this application, but the number of working quarries has decreased and will not be able to keep pace with demand. Use of recycled aggregates will extend the reserves of limestone and prevent imported aggregates having to be used for this lower value application.

Laboratory testing indicates that EW, CDW and IBA should all be suitable for use as unbound subbase (Hassan et al, 2013). Field trials are required to demonstrate that this can be achieved in practice. A trial of recycled aggregates as unbound subbase will be carried out at Rawdat Rashid in 2014, utilising EW and CDW. A separate trial of IBA will be carried out at the DSWMC at a later date.

\section{Next Steps}

The aim of the project is to support the rapidly developing infrastructure in Qatar by developing innovative methods and technologies for the use of recycled and secondary aggregate (RSA) in construction. The laboratory testing and site trials have demonstrated the potential of RSA to make a significant contribution to aggregate use in Qatar. However, in order to achieve this, a number of actions will be required.

First, further trials of RSA in a range of different applications should be carried out; it is unrealistic to expect industry to change its method of working on the basis of one 
trial, however successful. A wider range of trials on actual construction projects will be required, including applications as unbound subbase, CBM and pavement concrete. The project team is currently arranging these. The existing building trial will be extended, so as to assess the longer term durability of the concrete containing RSA.

The next important action is to update the Qatar Construction Specification (QCS) to enable wider use of RSA. The QCS is currently undergoing a major review and as part of this a number of changes have been suggested for use in unbound applications and concrete. The proposed changes for use in concrete are shown in Table 6.

Table 6. Proposed changes to the Qatar Construction Specification for concrete

\begin{tabular}{|c|c|c|}
\hline Item & QCS 2010 & Suggested change \\
\hline $\begin{array}{c}\text { Recycled aggregate } \\
\text { permitted }\end{array}$ & C20 max & C40 max \\
\hline Fines content $(<63 \mu \mathrm{m})$ & Coarse: $1.5 \% \max$ & Coarse: $2 \% \max$ \\
& Fine: $5 \% \max$ & Fine: $7 \%$ max \\
\hline Quality of fines & $\begin{array}{c}\text { Sand Equivalent test: } 70 \% \\
\text { min }\end{array}$ & $\begin{array}{c}\text { Methylene blue adsorption } \\
\text { value: } 1.0 \text { max }\end{array}$ \\
\hline Density (apparent) & 2.6 min & 2.0 min \\
\hline Foreign materials & Lightweight: $0.5 \%$ max & By weight and volume \\
\hline
\end{tabular}

The next step is to provide guidance for designers, contractors and producers on how to use recycled and secondary aggregates in construction, particularly in concrete where changes to standard mix designs will be required. This guidance will be provided in a best-practice document as the final deliverable from the project in late 2014. This will be updated as experience becomes available from further trials.

To change behaviour in industry, it will be necessary to demonstrate the benefits of using RSA. This will be done in both economic and environmental terms, by demonstrating the cost savings and reductions in greenhouse gas emissions by using locally produced RSA rather than importing primary aggregate. The savings for both cost and greenhouse gases arise principally due to the transport that can be avoided by not shipping the primary product from the UAE to Qatar.

The new producer at Rawdat Rashid (Lafarge-Qatar) has implemented a quality control system to ensure that the processed EW and CDW meet the requirements of the relevant standards and the QCS. A similar system will need to be implemented by Keppel Seghers at the DSWMC if the IBA is to be used in concrete block production or as unbound subbase. Concrete producers will need to make adjustments to their facilities to enable the use of EW, CDW and crushed rock fines in blends with primary aggregates and washed sand respectively.

If the changes described above are to be implemented, the government of Qatar will need to take a lead by setting a target for recycled and secondary aggregate production and by ensuring that adequate quality control systems are implemented by producers and testing companies. This should be done in the context of the Qatar National Development Strategy 2011 - 2016, which is currently being reviewed. A specific target for recycling of construction, demolition and excavation material should be set in the review. A suitable target might be to recycle $50 \%$ of all material arriving at 
Rawdat Rashed as aggregate by 2016. This would give a target of about 6.25 million tonnes per year.

A strategy for sustainable aggregate supply should also be developed, to cover issues such as the quantity and quality of imported aggregate, use of recycled and secondary aggregates, crushed rock fines as partial replacement for washed sand in fine aggregate, and removal of gypsum from sand to enable greater use of reserves in Qatar. The management of waste from the construction industry should form part of the overall strategy. This should include requirements for a soft strip of buildings to be carried out before demolition, and other measures to enable better recovery of the hard construction, demolition and excavation material as recycled aggregate.

There is growing awareness in government and the construction industry in Qatar of the need to use the abundant reserves of recycled and secondary materials, reduce reliance on costly imported aggregates and protect the environment. The building trials have generated a lot of interest and received the Qatar Contractors Forum Award as the "Qatar Most Innovative Project of the Year 2013" (Qatar Tribune, 2013). There is clearly an opportunity to make good use of recycled and secondary aggregates if the trials continue to be successful and if the issues described above are addressed.

\section{Conclusions}

Following a programme of laboratory testing, a site trial of recycled and secondary aggregates was carried out in Doha, Qatar in May and June 2013. Three trial onestory buildings, $2.5 \mathrm{~m} \times 2.5 \mathrm{~m}$ in plan were constructed adjacent to each other at the Ashghal - Najma site (B-Ring Road). The recycled and secondary aggregates were used to replace different proportions of natural aggregate in structural (C40) concrete and non load-bearing concrete blocks (average compressive strength 7.0 $\mathrm{MPa}$ ).

The trials were successfully constructed, although special measures were required to produce the blend of excavation waste (EW) and gabbro as coarse aggregate. The performance of the buildings has been monitored for one year through tests on cubes and cores. The results indicate improved strength and durability for the structural concrete and concrete blocks constructed with recycled and secondary aggregates compared to the control constructed with primary gabbro aggregate. The recycled and secondary aggregates could thus potentially be used in a range of applications, including pavement concrete and unbound subbase.

The move from a construction industry using only imported primary aggregates to one using a significant proportion of recycled and secondary aggregates, often in blends with primary aggregates, will require major changes to current practice and will take several years to achieve. However, it will lead to significant savings in cost and emissions of Greenhouse Gases (GHGs). It will also position Qatar as one of the leading nations in terms of use of recycled aggregates and will tie in with other sustainability initiatives being pursued by the government (Qatar National Development Strategy, 2011). The site trial has shown the possibilities and helped identify the issues which need to be addressed to achieve the changes and realise the benefits. 


\section{Acknowledgements}

The authors are grateful to the Qatar National Research Fund at Qatar Foundation for funding the project and to Dr Helen Viner of TRL for carrying out the technical review.

\section{References}

Abdelfatah, A.S. and S.W. Tabsh (2011). "Review of Research on and Implementation of Recycled Concrete Aggregate in the GCC". Advances in Civil Engineering, Volume 2011, Article ID 567924, doi:10.1155/2011/567924. Hindawi Publishing Corporation.

BS 1881-122 (2011). Testing concrete. Method for determination of water absorption". British Standards Institution, London, UK.

BS EN 12390-3 (2009). "Testing hardened concrete. Compressive strength of test specimens”. British Standards Institution, London, UK.

BS EN 771-3 (2011). "Specification for masonry units. Aggregate concrete masonry units (dense and lightweight aggregates)". British Standards Institution, London, UK. Construction Week Online, 21 January 2013. "Recycled aggregate use set to grow". Accessed at http://www.constructionweekonline.com/article-20436-recycledaggregates-use-set-to-grow/1/, 31/07/2014.

Fourniadis, I. (2010). "Geotechnical characterisation of the Simsima Limestone (Doha, Qatar)". In GeoShanghai International Conference 2010, pp273-278. ASCE Geotechnical Special Publication No. 204.

Hassan, K. E., A-Kuwari, M. S., Reid, J. M., Berhane, A. and Collis, C. (2013). "Developing the use of recycled and secondary aggregates in Qatar". The International Journal of Pavement Engineering and Asphalt Technology (PEAT) ISSN 1464-8164, Volume 14, Issue 1, May 2013, pp24-46.

Qatar Construction Specification (QCS) (2010). "Qatar National Construction Standards". Laboratories and Standardization Affairs - Ministry of Environment, Qatar Standards, Doha, Qatar.

Qatar General Secretariat for Development Planning (QSDP) (2011). "Qatar National Vision 2030". Gulf Publishing and Printing Company, Doha.

Qatar General Secretariat for Development Planning (QSDP) (2011). "Qatar National Development Strategy 2011-2016 - towards Qatar National Vision 2030". Gulf Publishing and Printing Company, Doha.

Qatar Foundation (2012). Qatar National Research Strategy. Qatar Foundation, Doha, Qatar. Available at http://www.qf-research-division.org/images/QNRS_2012.pdf.

QPMC (2013). Personal communication with David Matyus - Technical Director at Qatar Primary Materials Company. 
Qatar Tribune (2013). "Best innovative research award for MoE, TRL". Article published online, Monday $7^{\text {th }}$ October 2013.

Walker, M. J. (ed.) (2012). "Hot Deserts: Engineering, Geology and Geomorphology", Geological Society Engineering Geology Special Publication No. 25, ed. M J Walker, The Geological Society, London. 